\title{
Iridium-catalyzed 1,3-dipolar cycloadditions
}

\author{
Daniel Carmona and Luis A. Oro
}

Instituto Universitario de Catálisis Homogénea, Instituto de Ciencia de Materiales de Aragón, University of Zaragoza-CSIC, Pedro Cerbuna 12, 50009 Zaragoza, Spain e-mail: dcarmona@unizar.es

\begin{abstract}
Dipolar cycloaddition reactions (DCR) are atom-economic processes that permit the construction of heterocycles. Their enantioselective versions allow for the creation of up to four adjacent chiral centers in a concerted fashion. In particular, well-defined half-sandwich iridium (III) catalysts have been applied to the DCR between enals or methacrylonitrile with nitrones. Excellent yield and stereoselectivities have been achieved. Support for mechanistic proposals stems from the isolation and characterization of the true catalysts.
\end{abstract}

Keywords 1,3-Dipolar cycloadditions, Iridium catalysts, Nitrones, Enals, Methacrylonitrile

\section{Contents}

1 Introduction

2

1.1 The frontier molecular orbital theory ..................................... 3

2 DCR of nitrones with methacrolein.................................... 4

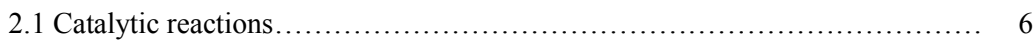

2.2 The catalytic cycle................................................ 8

2.3 Origin of the enantioselectivity .......................................... 8

3 DCR of nitrones with $\boldsymbol{\alpha}, \boldsymbol{\beta}$-unsaturated aldehydes........................... 9

4 DCR of nitrones with methacrylonitrile.................................... 11

4.1 Recycling experiments................................................. 13

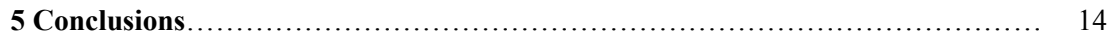

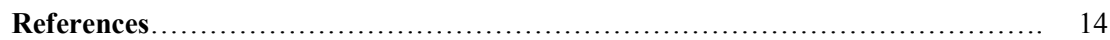




\section{Introduction}

Cycloaddition reactions are a fundamental class of processes in synthetic chemistry. Within this class, the 1,3-dipolar cycloaddition reaction (DCR) has found extensive use as an efficient method for the synthesis of different heterocyclic compounds. These type of reactions involve the addition of a 1,3dipole to a multiple $\pi$-bond system (dipolarophile) leading to five-membered heterocycles (Scheme 1) [1].

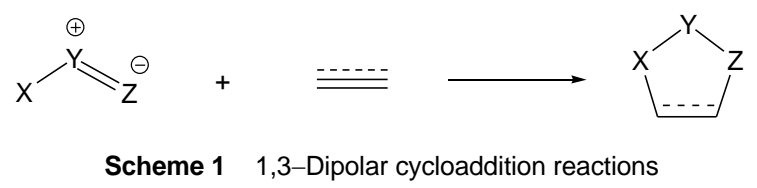

Huisgen in the 1960s undertook a systematic study that led to the generalization and classification of DCR [2] and to the proposal of a concerted synchronous mechanism (Scheme 2) [3]. However, Firestone considered the DCR to proceed via a stepwise diradical mechanism. Stereochemistry would be retained for short-lived diradical intermediates but may be destroyed for longerlived diradicals (Scheme 3) [4]. Currently, the most widely accepted mechanism is a concerted process with both new bonds being formed at the same time but not necessarily to the same extent. Additionally, very recently, Houk et al. have found an unambiguous correlation between the calculated activation barriers and the distortion energies, the latter being "the energy required to distort the 1,3-dipole and the dipolarophile from their equilibrium geometries into the transition-state geometries without allowing any interaction between them" [5]. These findings provide a new way of understanding the DCR that cannot be neglected in accurate computational studies [6-8].

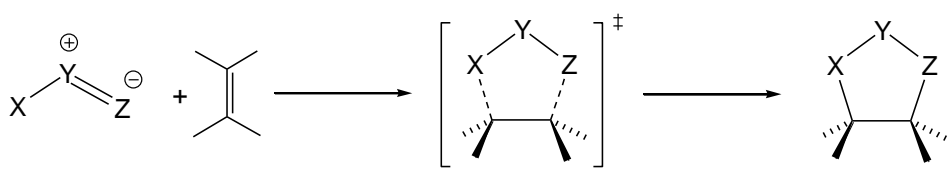

Scheme 2 Concerted mechanism for DCR

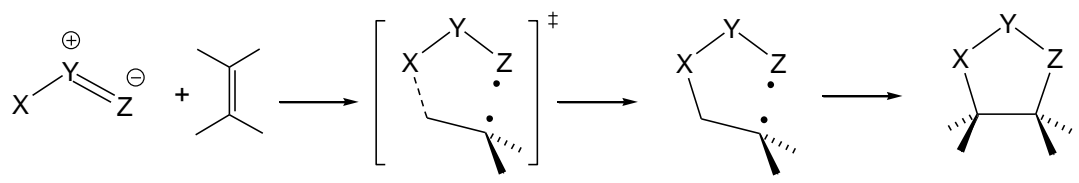

Scheme 3 Stepwise diradical mechanism for DCR 


\subsection{The frontier molecular orbital theory}

The most successful qualitative model for DCR is based on frontier molecular orbital (FMO) theory. According to this theory, reaction takes place by maximizing overlap between the HOMO and LUMO of the reagents. Sustman applied FMO theory to the reactivity of concerted DCR and classified them into three types depending on the interactions established between the FMO of the dipole and dipolarophile (Figure 1) [9-12]. Type I reactions involve dipoles with high-lying HOMO and dipolarophiles with low-lying LUMO. The most favorable FMO interaction will imply transference of charge from the nucleophilic dipole to the electrophilic dipolarophile. In this case, the reaction rate may be increased, for example, introducing electron-withdrawing groups on the dipolarophile. By the contrary, type III reactions involve dipoles with low-lying LUMO and dipolarophiles with high-lying HOMO. The dominant FMO interaction will take place between the HOMO of the dipolarophile and the LUMO of the dipole. Reactions of this type can be accelerated by using dipolarophiles with electron-donating groups. Finally, type II reactions involve dipoles and dipolarophiles with similar energy gaps between the HOMO and LUMO. These reactions are called ambiphilic and, in particular, reactions of nitrones with alkenes belong to this type. Introduction of electron-donating or electron-withdrawing substituents on the dipole or the dipolarophile can alter the relative FMO energies resulting in a change to type I or III reaction.

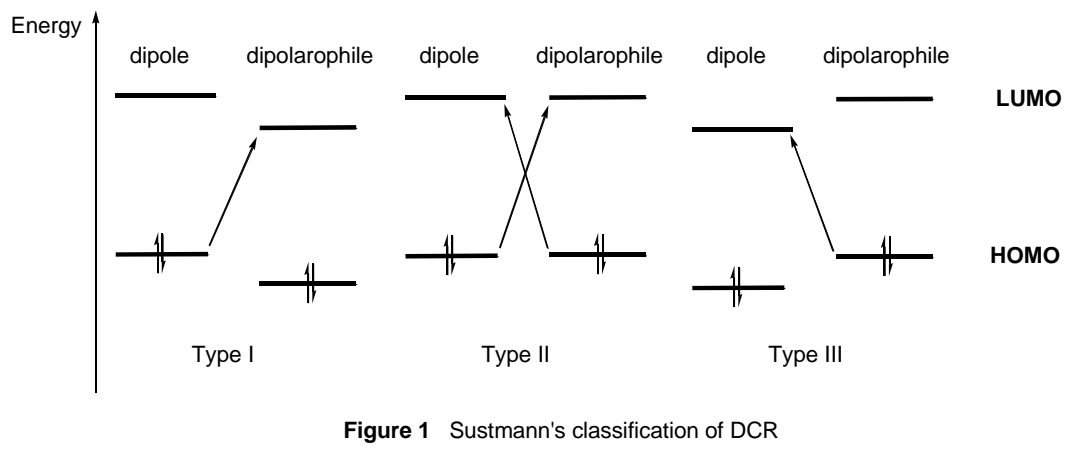

Interestingly, the presence of metallic Lewis acids in the reaction media may substantially affect reactions. When coordinating to the dipolarophile, the Lewis acid lowers the energy of its frontier orbitals. This lowering reduces the energy gap between the LUMO of the dipolarophile and the HOMO of the dipole (Figure 2) leading to an acceleration of the cycloaddition. Similarly, coordination to the dipole reduces the energy difference between the HOMO of the dipolarophile and the LUMO of the dipole, this reduction resulting in an increment of the reaction rate. Notably, the efficiency of this Lewis acid interaction relies not only on the fastening of the reaction but also on the capability of 
metallic complexes to control the selectivities of the cycloaddition. Thus, a variety of Lewis acids based on metals have been employed as catalysts in stereoselective DCR often providing excellent results [13-22].

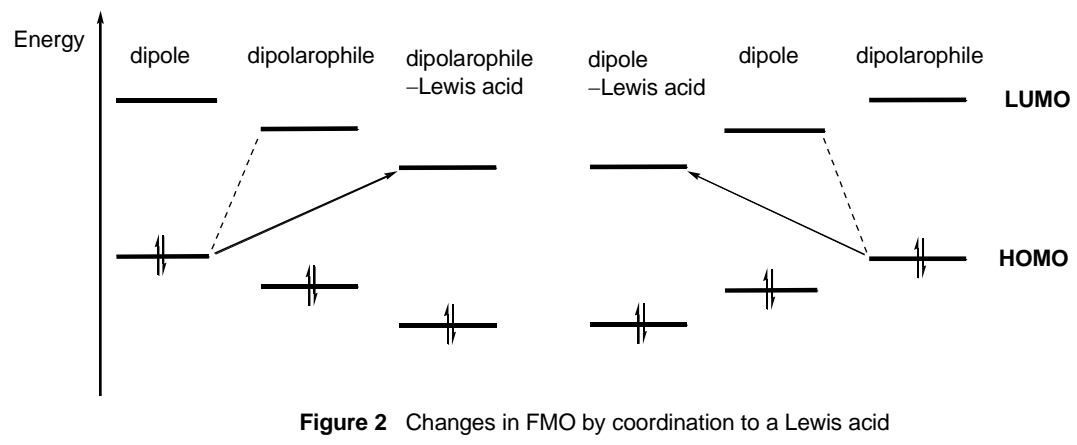

\section{DCR of nitrones with methacrolein}

Over the last years, one of the most studied DCR has been the asymmetric version of the cycloaddition of nitrones with alkenes. This reaction leads to the construction of up to three contiguous asymmetric carbon centers (Scheme 4). The resulting five-membered isoxazolidine derivatives may be converted into amino alcohols, alkaloids, or $\beta$-lactams. Several chiral metal complexes have been used as catalysts for this process [13-15, 18-22]. However, the employ of iridium derivatives is very scarce.

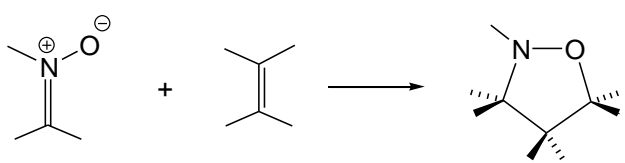

Scheme 4 DCR between nitrones and alkenes

In 2005, it was published the enantioselective DCR of nitrones $\mathbf{I}-\mathbf{V}$ to methacrolein catalyzed by $\left(\eta^{5}-\mathrm{C}_{5} \mathrm{Me}_{5}\right) \operatorname{Ir}\{(R)-$ Prophos $\} \quad$ (Prophos $=1,2-$ bis(diphenylphosphino)propane) containing complexes (Scheme 5) [23]. As catalyst precursor the aqua-complex $\left(S_{\mathrm{Ir}}, R_{\mathrm{C}}\right)-\left[\left(\eta^{5}-\mathrm{C}_{5} \mathrm{Me}_{5}\right) \operatorname{Ir}\{(R)-\operatorname{Prophos}\}\right.$ $\left.\left(\mathrm{H}_{2} \mathrm{O}\right)\right]\left(\mathrm{SbF}_{6}\right)_{2}(\mathbf{1})$, prepared by treating the tris(solvento) complex [24] in acetone with an equimolar amount of $(R)$-Prophos in the presence of traces of water (Scheme 6), was employed. The reaction is completely diastereoselective: only one of the two possible epimers at metal was spectroscopically detected, in solution from $-90^{\circ} \mathrm{C}$ to $\mathrm{RT}$, and an X-ray determination showed that it was the $S$ at metal isomer. Methacrolein displaces coordinated water from 1 affording, also diastereoselectively, the enal complex $\left(S_{\mathrm{Ir}}, R_{\mathrm{C}}\right)-\left[\left(\eta^{5}-\mathrm{C}_{5} \mathrm{Me}_{5}\right) \operatorname{Ir}\{(R)-\right.$ Prophos $\}$ (methacrolein)] $\left(\mathrm{SbF}_{6}\right)_{2}$ (2) (Scheme 7) [23]. The presence of an electron withdrawing group on the dipolarophile $(\mathrm{CHO})$ together with the coordi- 


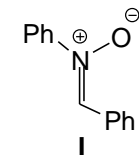

$\mathrm{Me}, \overbrace{\text { II }}^{\oplus}-\mathrm{O}^{\ominus}$

$\langle\stackrel{\oplus}{N}$

$\mathrm{o}^{\ominus}$

III

$+{ }^{\mathrm{Me}} \pi^{\mathrm{CHO}}$<smiles>[O-][N+]1=CCCCC1</smiles>

IV

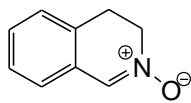

V

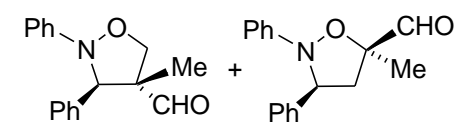

endo- $(3 R, 4 R) \quad$ endo- $(3 R, 5 R)$

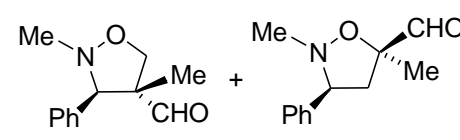

endo- $(3 R, 4 R) \quad$ endo- $(3 R, 5 R)$

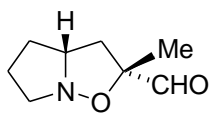

(+)-endo-(3R,5R)

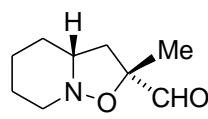

$(-)$-endo- $(3 R, 5 R)$

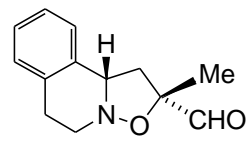

(-)-endo-(3S,5R)

Scheme 5 Major adducts for the DCR between nitrones I-V and methacrolein
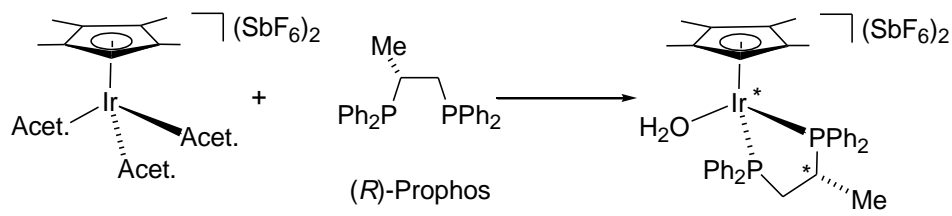

$\left(S_{\mathrm{l}}, R_{\mathrm{C}}\right)-1$

Scheme 6 Preparation of the catalyst precursor $\left(S_{\mid r}, R_{C}\right)-1$

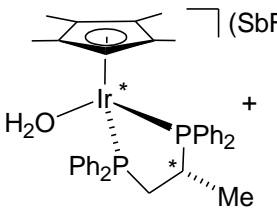

$\left(S_{\mathrm{Ir}}, R_{\mathrm{C}}\right)-\mathbf{1}$

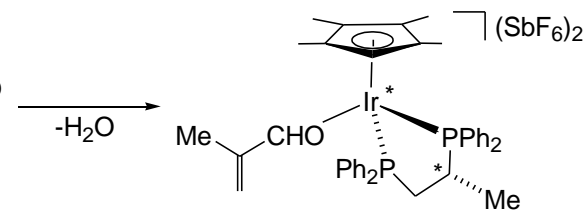

$\left(S_{\mathrm{lr}}, R_{\mathrm{C}}\right)-\mathbf{2}$

Scheme 7 Preparation of the methacrolein complex $\left(S_{\mid r}, R_{\mathrm{C}}\right)-2$ 
nation to the metal make the process a Sustmann's type I reaction and, accordingly, electronic density will be transferred from the nitrone to the methacrolein. In such a process, to achieve good yield, coordination of the dipole (nitrone) has to be avoided. Nitrones may coordinate metals through their oxygen atom and, in fact, while acyclic nitrones I and II do not displace methacrolein from complex $\mathbf{2}$, the cyclic ones III-V readily substitute the coordinated dipolarophile even at low temperature. As we will comment later, to avoid this negative effect concentration of cyclic nitrones has to be maintained low during catalysis.

\subsection{Catalytic reactions}

Complex 2 efficiently catalyzes the cycloaddition reaction of methacrolein with the nitrones $\mathbf{I}-\mathbf{V}$. Table 1 lists some results obtained. The reactions were performed in $\mathrm{CH}_{2} \mathrm{Cl}_{2}$ in the presence of $4 \AA$ molecular sieves, with $5 \mathrm{~mol} \%$ of catalyst loading and a 1/140/20 catalyst/methacrolein/nitrone molar ratio. Ty-

Table 1 Enantioselective DCR of methacrolein with nitrones I-V

\begin{tabular}{ccccccc}
\hline Entry & Nitrone & $\mathbf{t}(\mathbf{h})$ & Yield (\%) & 3,4-endo & 3,5-endo & Ee (\%) \\
\hline 1 & I & 10 & 100 & 82 & 18 & $95 / 85.5$ \\
2 & II & 24 & 78 & 2 & 98 & $--/ 93$ \\
3 & III & 15 & 100 & -- & 100 & 86 \\
4 & IV & 15 & 100 & -- & $>99$ & 92 \\
5 & V & 15 & 100 & -- & 100 & 93 \\
6 & III & 16 & 75 & & $>99$ & 76 \\
\hline
\end{tabular}

pically, quantitative yields are obtained after a few hours at $-25^{\circ} \mathrm{C}$. The acyclic nitrone II generates the less active system but, even so, $78 \%$ conversion was achieved after $24 \mathrm{~h}$ at $-10^{\circ} \mathrm{C}$ (entry 2). Enantiomeric excesses greater than $90 \%$ were achieved in most cases. A greater excess of methacrolein improves both rate and enantioseletivity (compare entry 6 with a catalyst/methacrolein/nitrone molar ratio $1 / 28 / 20$ with entry 3 with a $1 / 140 / 20$ molar ratio). To avoid undesired nitrone coordination, addition of the cyclic nitrones III-V was accomplished over 10 hours.

Temperature variation slightly affected both product distribution and enantioselectivity, the later smoothly increasing as temperature decreases (Table 2). Thus, for example, the ee of the 3,4-endo adduct of the DCR between methacrolein and nitrone I gradually increases from 85 to $96 \%$ when temperature decreases from +5 to $-35^{\circ} \mathrm{C}$ (entries 1 to 5 ). A similar trend was observed for the 3,5-adduct as well as for the DCR involving other nitrones (Table 2).

$A b$ initio calculations carried out by Tanaka and Kanemasa conclude that, under Lewis acid catalyzed conditions, the formation of endo-cycloadducts is preferred and that the attack of nucleophilic nitrone oxygen should become 
Table 2 Effect of the temperature

\begin{tabular}{cccccccc}
\hline Entry & Nitrone & $\mathbf{T}(\mathbf{(} \mathbf{C})$ & $\mathbf{t}(\mathbf{h})$ & yield $(\%)$ & 3,4-endo & 3,5-endo & ee (\%) \\
\hline 1 & I & +5 & 6 & 100 & 58 & 42 & $85 / 79$ \\
2 & I & -5 & 7 & 100 & 71 & 29 & $91 / 81$ \\
3 & I & -15 & 8 & 100 & 78 & 22 & $93.5 / 82$ \\
4 & I & -25 & 10 & 100 & 82 & 18 & $95 / 85.5$ \\
5 & I & -35 & 24 & 100 & 86.5 & 13.5 & $96 / 87$ \\
6 & II & 0 & 15 & 78 & 5 & 95 & $--/ 88$ \\
7 & II & -10 & 24 & 78 & 2 & 98 & $--/ 93$ \\
8 & III & -25 & 15 & 100 & -- & 100 & 86 \\
9 & III & -35 & 24 & 55 & -- & 100 & 91 \\
10 & V & -25 & 15 & 100 & -- & $>99$ & 93 \\
11 & V & -35 & 24 & 53 & -- & 100 & 95 \\
\hline
\end{tabular}

more favored to occur at the $\beta$-position of the enal rendering 3,4-cycloadducts [25]. In the iridium system we are referring to, reactions occur with perfect endo selectivity. With respect to the regioselectivity, while the uncatalyzed reaction of nitrone I with methacrolein gives the 3,5-endo adduct, the major product of the catalyzed reaction is the 3,4-endo cycloadduct, in good agreement with Tanaka and Kanemasa calculations. On the other hand, cyclic nitrones III-V, which are more sterically demanding in their endo-approach to coordinated methacrolein, render 3,5-cycloadducts in all cases [26, 27].

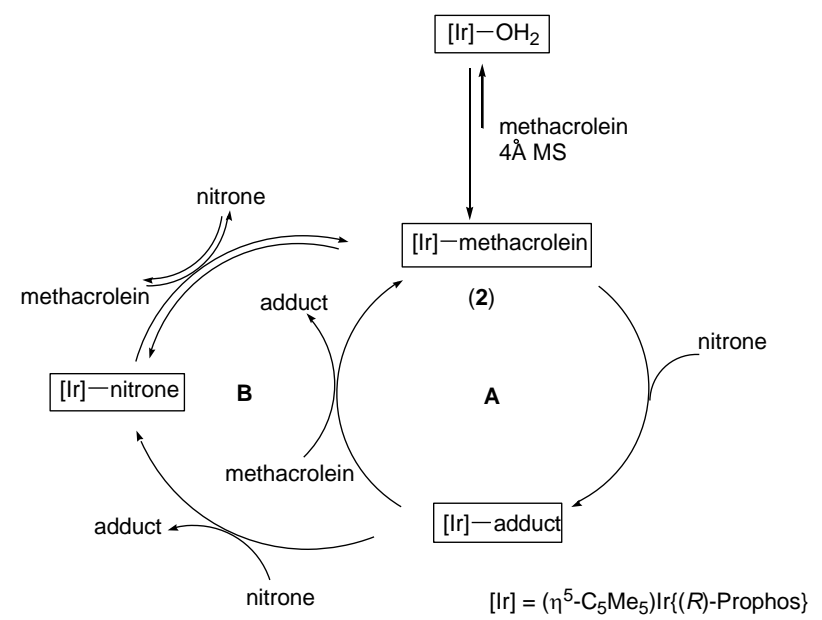

Scheme 8 Proposed catalytic cycle 


\subsection{The catalytic cycle}

The catalytic cycle that has been proposed [23] is depicted in Scheme 8. At $-25^{\circ} \mathrm{C}$, the resting state of the catalyst is the [Ir]-methacrolein complex 2 that is the true catalyst. Its reaction with the nitrone is the key step of the productive cycle $\mathbf{A}$ : it is the rate and enantioselectivity determining step, at this temperature. For cyclic nitrones, path $\mathbf{B}$ becomes operative diminishing the concentration of the active species and, therefore, decreasing the rate. Lowering nitrone concentration (slow addition) hinders this undesired side reaction and, although it also slows down the rate of formation of the [Ir]-adduct intermediate, overall it favors the catalytic process. It has been experimentally shown that the catalytic rate increases when methacrolein concentration increases. Scheme 8 explains this effect because increasing this concentration favors the adduct elimination in path $\mathbf{A}$ and it recuperates the inactive metallic concentration, present as [Ir]-nitrone in path $\mathbf{B}$, by shifting the [Ir]-nitrone/[Ir]methacrolein equilibrium towards the enal complex which restarts the cycle.

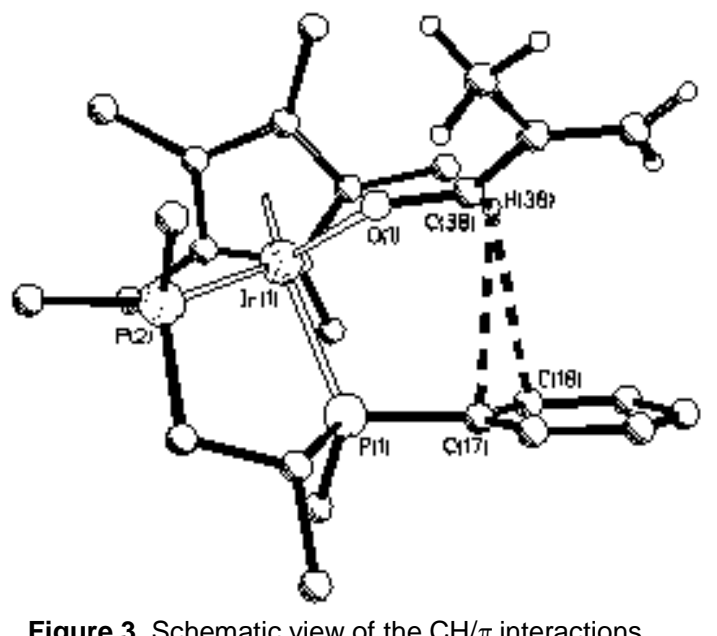

Figure 3 Schematic view of the $\mathrm{CH} / \pi$ interactions in the cation of complex 2

\subsection{Origin of the enantioselectivity}

The $\left(\eta^{5}-\mathrm{C}_{5} \mathrm{Me}_{5}\right) \operatorname{Ir}\{(R)-$ Prophos $\}$ system is very selective for the DCR of nitrones and methacrolein with enantioselectivity up to $96 \%$ ee. A few structural features of the cation of the catalyst, $\left[\left(\eta^{5}-\mathrm{C}_{5} \mathrm{Me}_{5}\right) \operatorname{Ir}\{(R)-\right.$ Prophos $\}$ (methacrolein) $]^{2+}$, account for the encountered selectivity. First, in spite of $(R)$-Prophos being a $\mathrm{C}_{1}$ symmetric ligand, the $S$ at metal epimer of the catalyst is formed with complete diastereoselectivity. Moreover, although, in 
some instances, epimerization at the metal in chiral half-sandwich transition metal complexes is a low-demanding energy process [28], this isomerization is not observed for this complex. Second, all the diffractometric and spectroscopic data support a $\lambda$ conformation for the $\mathrm{Ir}-\mathrm{P}-\mathrm{C}-\mathrm{C}-\mathrm{P}$ five-membered metallacycle formed on coordination of the $(R)$-Prophos ligand. The bulky $\mathrm{C}_{5} \mathrm{Me}_{5}$ ring constrains this conformation forcing the methyl substituent to occupy the less hindered pseudoequatorial position. This conformation, together with the $S$ configuration at the metal, determines the chiral bias of the catalyst pocket in which catalysis takes place. Third, methacrolein coordinates to the metallic fragment in the $E$ geometry and it adopts an s-trans conformation [29-31]. This conformation, which is also preferred for uncomplexed methacrolein [32], is reinforced by coordination and retained in catalytic conditions. Fourth, $\mathrm{CH} / \pi$ attractive interactions between the $\mathrm{CHO}$ aldehyde proton and the pro- $S$ phenyl ring of the $(R)$-Prophos ligand (Figure 3) establish the methacrolein rotamer around the $\mathrm{M}-\mathrm{O}$ bond both in the solid state and in solution. Overall, the geometry of the methacrolein is set and, in the chiral environment in which it is located, its $R e$-face becomes much more accessible to the nitrone than its $\mathrm{Si}$ face, which is shielded by the phenyl rings of the $(R)$-Prophos ligand. This situation seems also to apply for the transition-state assembly of the DCR and accounts for the outcome of the catalytic reaction.

\section{DCR of nitrones with $\alpha, \beta$-unsaturated aldehydes}

As a consequence of the coordination ability of nitrones to Lewis acids, the metal-catalyzed asymmetric DCR of nitrones with electron poor alkenes has been focused on alkenes that enable a bidentate coordination to the Lewis acid. In sharp contrast, examples of one point binding catalysts for the activation of electron deficient monofunctionalized alkenes are scarce [20, 23, 27, 33-46]. In this context, enal homologues of the methacrolein complex $\left[\left(\eta^{5}-\mathrm{C}_{5} \mathrm{Me}_{5}\right) \mathrm{Ir}\right.$ $\{(R)-$ Prophos $\}$ (methacrolein) $]\left(\mathrm{SbF}_{6}\right)_{2}(2)$ have been employed in the DCR between nitrones and enals [41].

Complexes of the formula $\left(S_{\mathrm{Ir}}, R_{\mathrm{C}}\right)-\left[\left(\eta^{5}-\mathrm{C}_{5} \mathrm{Me}_{5}\right) \operatorname{Ir}\{(R)-\operatorname{Prophos}\}\right.$ (enal) $]$ $\left(\mathrm{SbF}_{6}\right)_{2}(3-8)$ can be diastereoselectively prepared by addition of the appropriate enal to the water complexes $\left(S_{\mathrm{Ir}}, R_{\mathrm{C}}\right)-\left[\left(\eta^{5}-\mathrm{C}_{5} \mathrm{Me}_{5}\right) \operatorname{Ir}\{(R)-\operatorname{Prophos}\}\left(\mathrm{H}_{2} \mathrm{O}\right)\right]$ $\left(\mathrm{SbF}_{6}\right)_{2}$ in the presence of $4 \AA$ molecular sieves (Scheme 9).

One interesting feature of the ${ }^{1} \mathrm{H}$ NMR spectra of these complexes is the strong shielding of the aldehyde proton resonance after coordination. At $-25^{\circ} \mathrm{C}$ in $\mathrm{CD}_{2} \mathrm{Cl}_{2}$ solution, this proton resonates in the range $6.93-7.50 \mathrm{ppm}$, about 2.3 ppm shifted to higher field with respect to the corresponding free enals. It has been shown that a comparable shift, measured in the related $\left(S_{\mathrm{Ir}}, R_{\mathrm{C}}\right)-\left[\left(\eta^{5}-\right.\right.$ $\left.\mathrm{C}_{5} \mathrm{Me}_{5}\right) \operatorname{Ir}\{(R)$-Prophos $\}$ (methacrolein) $]\left(\mathrm{SbF}_{6}\right)_{2}$ complex, is concomitant to the existence of $\mathrm{CH} / \pi$ interactions between the $\mathrm{CHO}$ proton and one of the phenyl rings of the Profos ligand [23]. Therefore, it is likely that these interactions are also operating in complexes 3-8. In addition NOESY experiments show enhan- 


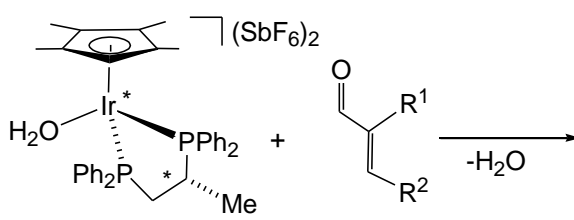

$\left(S_{\mathrm{r}}, R_{\mathrm{C}}\right)-1$

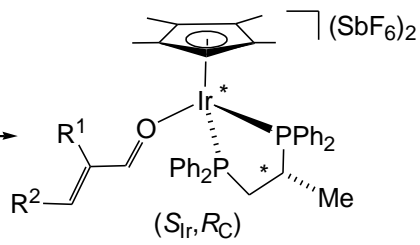

$\mathrm{R}^{1}=\mathrm{R}^{2}=\mathrm{H}(\mathbf{3})$

$\mathrm{R}^{1}=\mathrm{H}, \mathrm{R}^{2}=\mathrm{Me}(\mathbf{4})$

$\mathrm{R}^{1}=\mathrm{Me}, \mathrm{R}^{2}=\mathrm{Me}(\mathbf{5}$

$\mathrm{R}^{1}=\mathrm{Me}, \mathrm{R}^{2}=\mathrm{Et} \quad(6)$

$\mathrm{R}^{1}, \mathrm{R}^{2}=-\left(\mathrm{CH}_{2}\right)_{4^{-}}(\mathbf{7})$

$\mathrm{R}^{1}=\mathrm{H}, \mathrm{R}^{2}=\mathrm{Ph}(\mathbf{8})$

Scheme 9 Preparation of the enal complexes

cement patterns compatible only with an s-trans conformation for the coordinated enal and a $\lambda$ conformation for the $\mathrm{Ir}-\mathrm{P}-\mathrm{C}-\mathrm{C}-\mathrm{P}$ five-membered metallacycle. In summary, the NMR data indicate that the conformation of both metallic fragment and enal are significantly hampered when the enal is coordinated to the metal into the chiral pocket defined by the $\left(\mathrm{C}_{5} \mathrm{Me}_{5}\right) \operatorname{Ir}\{(R)-$ Prophos $\}$ moiety. Thus, they are excellent candidates to be tested as catalyst for DCR: the enals present a restricted conformation and, furthermore, they are activated by coordination to the metal. In fact, most of them efficiently catalyze the cycloaddition reaction of the nitrones $N$-benzylidenphenylamine $N$ -

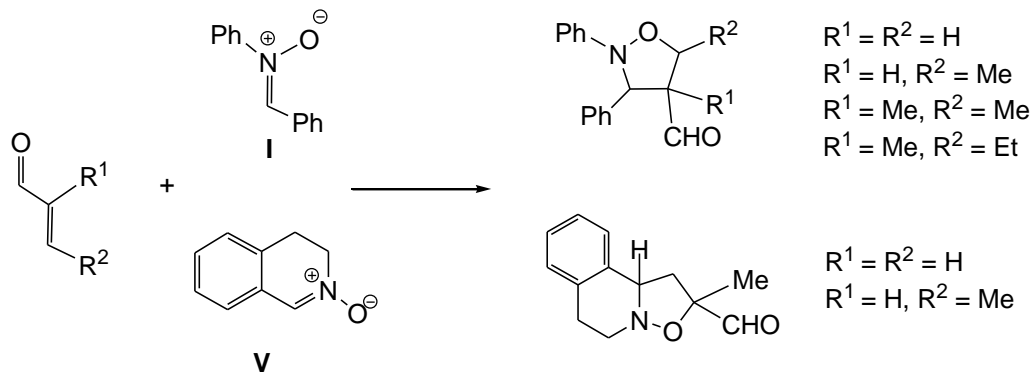

Scheme 10 1,3-Dipolar cycloaddition reactions

Table 3 Enantioselective DCR of enals with nitrones I and V

\begin{tabular}{ccccccc}
\hline Entry & Catalyst & Nitrone & $\mathbf{T ~ ( o} \mathbf{C})$ & $\mathbf{t}(\mathbf{h})$ & yield (\%) & ee (\%) \\
\hline 1 & $\mathbf{3}$ & $\mathbf{I}$ & -25 & 16 & 100 & 90 \\
2 & $\mathbf{4}$ & $\mathbf{I}$ & -25 & 25 & 100 & 84.5 \\
3 & $\mathbf{5}$ & $\mathbf{I}$ & -25 & 72 & 96.5 & 92 \\
4 & $\mathbf{6}$ & $\mathbf{I}$ & -10 & 72 & 100 & 84.5 \\
5 & $\mathbf{6}$ & $\mathbf{I}$ & -25 & 72 & 55 & 94 \\
6 & $\mathbf{3}$ & $\mathbf{V}$ & -25 & 25 & 69 & 66 \\
7 & $\mathbf{4}$ & $\mathbf{V}$ & -25 & 25 & 100 & 70 \\
\hline
\end{tabular}


oxide (I) and 3,4-dihydroisoquinoline $\mathrm{N}$-oxide (V) to the corresponding enal (Scheme 10). Table 3 lists a selection of the results. Catalyst were prepared in situ by treating the aqua precursors $\left(S_{\mathrm{Ir}}, R_{\mathrm{C}}\right)-\left[\left(\eta^{5}-\mathrm{C}_{5} \mathrm{Me}_{5}\right) \operatorname{Ir}\{(R)-\right.$ Prophos $\left.\}\left(\mathrm{H}_{2} \mathrm{O}\right)\right]\left(\mathrm{SbF}_{6}\right)_{2}$ with the corresponding enal in the presence of $4 \AA$ MS.The reactions were performed in $\mathrm{CH}_{2} \mathrm{Cl}_{2}$, in the presence of $4 \AA$ molecular sieves, with $10 \mathrm{~mol} \%$ of catalyst loading and a 1/70/10 catalyst/enal/nitrone molar ratio. The 1-cyclohexen-1-carboxaldehyde (7) and transcinnamaldehyde (8) derivatives were not active. The cyclic nitrone $\mathbf{V}$ was added slowly to avoid undesired nitrone coordination (see above). Perfect diastereoselectivity for the endo isomer was observed in all cases and the 3,4 regioisomer was the sole adduct (nitrone I) or the major one (more than $90 \%$, nitrone V). The ee values achieved ranged from 66 to $94 \%$, enantioselectivity increasing as temperature decreases (compare entries 4 and 5).

The absolute configuration of the major adduct obtained from the reaction of trans-crotonaldehyde with nitrone I was determined as the $3 S, 4 R, 5 S$ isomer, by derivatization with $(R)-(-)-\alpha-$ methylbenzylamine [41]. Accordingly, the $R e$-face of the coordinated trans-crotonaldehyde has to be much more accesible to the nitrone than its $\mathrm{Si}$-face during the chirality induction step.

\section{DCR of nitrones with methacrylonitrile}

The problem of the competitive coordination between the nitrone and the alkene can be circumvented by using alkenes with a good coordinating functionality such as a cyano group. Thus, the DCR between nitrones IV and V (see Scheme 5) and methacrylonitrile was carried out using the aqua-complex $\left(S_{\mathrm{Ir}}, R_{\mathrm{C}}\right)-\left[\left(\eta^{5}-\mathrm{C}_{5} \mathrm{Me}_{5}\right) \operatorname{Ir}\{(R)-\operatorname{Prophos}\}\left(\mathrm{H}_{2} \mathrm{O}\right)\right]\left(\mathrm{SbF}_{6}\right)_{2}$ (1) as catalyst precursor $[42,46]$. The reactions were performed in $\mathrm{CH}_{2} \mathrm{Cl}_{2}$, with $10 \mathrm{~mol} \%$ of catalyst loading and a 1/70/20 catalyst/methacrylonitrile/nitrone molar ratio. In both cases, quantitative conversion to the 3,5-endo-cycloadduct are achieved but the system is not enantioselective (Table 4).

Table 4 Catalytic DCR of methacrylonitrile

\begin{tabular}{ccccc}
\hline Entry & Nitrone & Yield & 3,5-endo (\%) & ee (\%) \\
\hline 1 & IV & 91 & 100 & 1 \\
2 & V & 100 & 100 & 0 \\
\hline
\end{tabular}

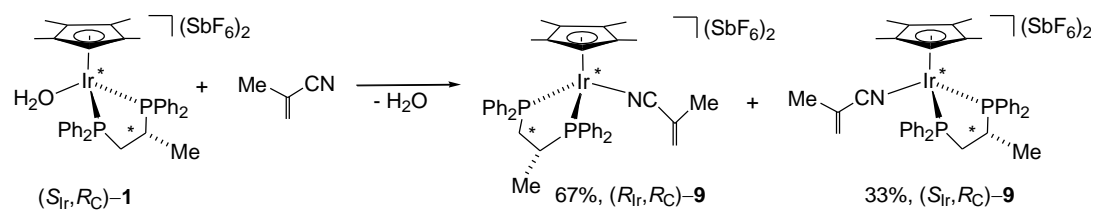

Scheme 11 Preparation of the methacrylonitrile complex 9 
Interesting information about the catalytic systems was obtained by studying the stereochemistry of the reaction of the catalyst precursor $\mathbf{1}$ with methacrylonitrile. The water molecule of complex $\mathbf{1}$ is readily diplaced by methacrylonitrile rendering complex $\left[\left(\eta^{5}-\mathrm{C}_{5} \mathrm{Me}_{5}\right) \operatorname{Ir}\{(R)-\operatorname{Prophos}\}\right.$ (methacrylonitrile)] $\left(\mathrm{SbF}_{6}\right)_{2}(9)$ as a mixture of the two possible epimers at metal namely, $R_{\mathrm{Ir}}, R_{\mathrm{C}}$ and $S_{\mathrm{Ir}}, R_{\mathrm{C}}$, in $34 \%$ diastereomeric excess in the former (Scheme 11). In acetone, at $50^{\circ} \mathrm{C}$, the $R_{\mathrm{Ir}}, R_{\mathrm{C}}$ isomer slowly epimerizes to the thermodynamically preferred $S_{\mathrm{I}}, R_{\mathrm{C}}$ epimer. From the solution, pure samples of the latter can be isolated that have been employed as stoichiometric catalysts for the DCR between methacrylonitrile and nitrones IV and $\mathbf{V}$.

Reaction of pure $\left(S_{\mathrm{Ir}}, R_{\mathrm{C}}\right)-\mathbf{9}$ with nitrones IV or $\mathbf{V}$ followed by the addition of an excess of $n-\mathrm{Bu}_{4} \mathrm{NBr}$ (Scheme 12) gives the corresponding 3,5-endoisoxazolidines in quantitative yield. Table 5 collects the ee values obtained for

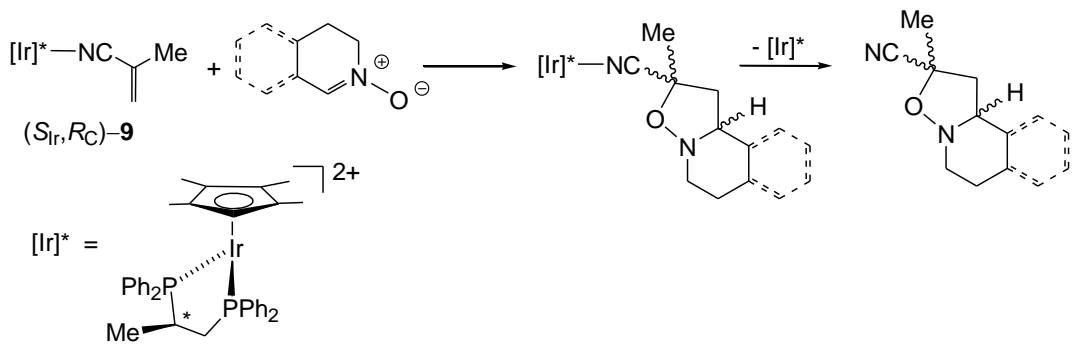

Scheme 12 Stoichiometric DCR between complex $\left(S_{\mid r}, R_{\mathrm{C}}\right)-\mathbf{9}$ and nitrones IV and V

Table 5 Stoichiometric reactions

\begin{tabular}{llll}
\hline Entry & Nitrone & Temp. & ee (\%) \\
\hline 1 & IV & RT & 84 \\
2 & V & RT & 74 \\
3 & IV & $0^{\circ} \mathrm{C}$ & 93,5 \\
\hline
\end{tabular}

the two nitrones. Comparison of the results of Table 5 with those of Table 4 indicates that whereas a mixture of epimers complex $9\left(67 \% R_{\mathrm{Ir}}, R_{\mathrm{C}} / 33 \% S_{\mathrm{Ir}}, R_{\mathrm{C}}\right.$, molar ratio) reacts with nitrones 2,3,4,5-tetrahydropyridine $N$-oxide (IV) or 3,4-dihydroisoquinoline $N$-oxide (V) rendering regio- and diastereoselectively racemates of the corresponding 3,5-cycloadducts (Table 4), pure $\left(S_{\mathrm{Ir}}, R_{\mathrm{C}}\right)-\mathbf{9}$ stoichiometrically catalyzes these reactions with 84 and $74 \%$ ee, respectively, (Table 5) at room temperature. At lower temperature greater ee are obtained (entry $3,0^{\circ} \mathrm{C}, 93.5 \%$ ee).

The impressive increase in the ee values achieved in stoichiometric reactions compared to those in catalytic runs strongly indicates that the configuration at the metal correlates with the stereochemistry of the catalytic outcome: only if $\left(R_{\mathrm{Ir}}, R_{\mathrm{C}}\right)-\mathbf{9}$ and $\left(S_{\mathrm{Ir}}, R_{\mathrm{C}}\right)-\mathbf{9}$ diverge in enantioselection it is possible to 
achieve zero ee working with $R_{\mathrm{Ir}}, R_{\mathrm{C}} / S_{\mathrm{Ir}}, R_{\mathrm{C}}$ mixtures and up to $93.5 \%$ ee using pure $\left(S_{\mathrm{Ir}}, R_{\mathrm{C}}\right)-\mathbf{9}$ as catalyst.

\subsection{Recycling experiments}

Pure $\left(S_{\mathrm{Ir}}, R_{\mathrm{C}}\right)-\mathbf{9}$ is a highly enantioselective catalyst for the DC reaction between methacrylonitrile and nitrones IV and $\mathbf{V}$ but only stoichiometric amounts of the product can be prepared in high enantioselectivity. To increase the ratio adduct/catalyst without loss of ee, recycling experiments in repetitive batch mode have been carried out. Scheme 13 shows the three steps of the procedure developed. In the first step, 5 equivalents of nitrone were added to diastereopure $\left(S_{\mathrm{II}}, R_{\mathrm{C}}\right)-\mathbf{9}$. After the required reaction time, excess of nitrone was extracted in $\mathrm{Et}_{2} \mathrm{O} / \mathrm{CH}_{2} \mathrm{Cl}_{2}$ to avoid the simultaneous presence of nitrone, alkene and catalyst in the reaction medium. Adduct was dissociated from the its iridium complex by adding 20 equivalents of alkene in the second step. Simultaneously, a $\left(R_{\mathrm{Ir}}, R_{\mathrm{C}}, S_{\mathrm{Ir}}, R_{\mathrm{C}}\right)-\mathbf{9}$ mixture was formed. The adduct and the excess of nitrile were extracted in $\mathrm{Et}_{2} \mathrm{O} / \mathrm{CH}_{2} \mathrm{Cl}_{2}$ and from the extract the adduct was recovered. In the third step, the $\left(R_{\mathrm{Ir}}, R_{\mathrm{C}}, S_{\mathrm{Ir}}, R_{\mathrm{C}}\right)-\mathbf{9}$ mixture was allowed to epimerize to $\left(S_{\mathrm{Ir}}, R_{\mathrm{C}}\right)-\mathbf{9}$ which restarts a further catalytic run. Following these procedure, in a second catalytic run, $\left(S_{\mathrm{Ir}}, R_{\mathrm{C}}\right)-9$ renders the cycloadduct in $93.5 \%$ yield and $92 \%$ ee. As it can be seen, both yield and ee are essentially maintained [47].

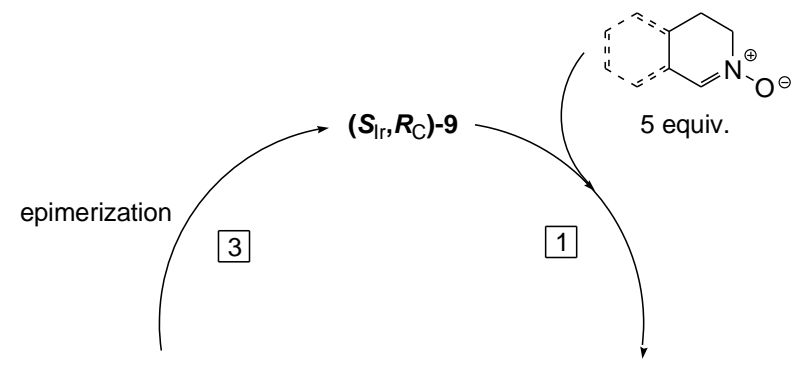

$\left(\boldsymbol{R}_{\mid \mathrm{r}}, \boldsymbol{R}_{\mathrm{C}}\right)-9+\left(\boldsymbol{S}_{\mathrm{l}}, \boldsymbol{R}_{\mathrm{C}}\right)-9$

[Ir]-adduct
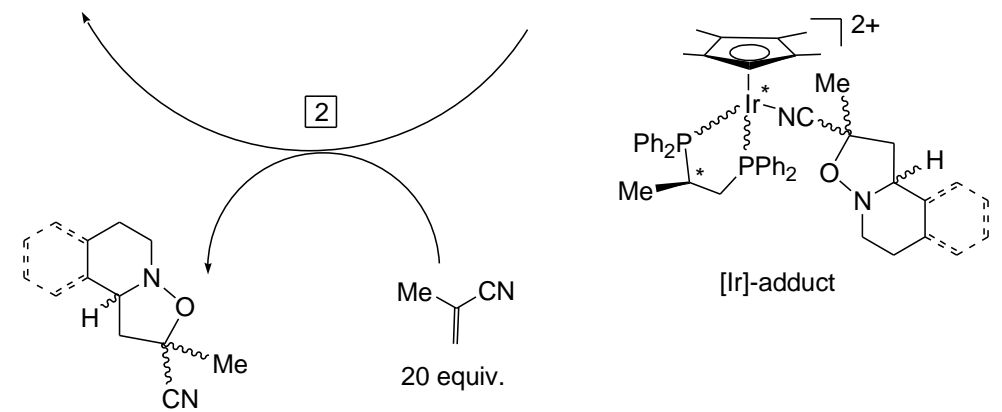

[lr]-adduct

Scheme 13 Recycling experiments 


\section{Conclusions}

Diastereomerically pure iridium complexes of the formula $\left[\left(\eta^{5}-\right.\right.$ $\left.\mathrm{C}_{5} \mathrm{Me}_{5}\right) \operatorname{Ir}\{(R)$-Prophos $\}($ activated alkene) $]\left(\mathrm{SbF}_{6}\right)_{2}$ (activated alkene = enal, methacrylonitrile) are active and selective catalysts for the DCR between one point binding activated alkenes and nitrones. Enals coordinate to the metal in a completely diastereoselective way with a restricted geometry. From the point of view of the selectivity, a key point in enal coordination is the establishment of $\mathrm{CH} / \pi$ attractive interactions between the $\mathrm{CHO}$ aldehyde proton and one $(R)-$ Prophos phenyl group. This interaction fixes the methacrolein rotamer around the $\mathrm{M}-\mathrm{O}$ bonds and renders the system enantioselective.

The above mentioned complexes are the sole iridium derivatives applied to DCR and the cycloaddition of nitrones to enals or methacrylonitrile the unique process studied. We think that iridium-based catalysts are underrepresented in 1,3-dipolar cycloaddition chemistry. For example, no iridium (I) systems have been developed to this end. It can be anticipated that the (bidentate ligand) $\operatorname{Ir}(\mathrm{I})$ fragment could be active (and stereoselective if chiral bidentate ligands are used) in DCR such as those involving azomethine ylides.

In summary, the development 1,3-dipolar cycloadditions will continue during the next years and the potential of iridium-based catalysts in this field is far from being exhausted.

Acknowledgments The authors thank financial support from Ministerio de Ciencia e Innovación (MICINN, Spain) and FEDER (Grant CTQ2009/10303BQU) and MULTICAT, Consolider Ingenio-2010 (CSD2009-00050).

\section{References}

1. Padwa, A. Intermolecular 1,3-Dipolar Cycloadditions, Comprehensive Organic Chemistry, Trost, B. M.; Fleming, I.; Semmelhack, M. F., Eds.; Pergamon: Oxford, 1991; Vol. 4 pp 1069-1109.

2. Huisgen, R. 1,3-Dipolar Cycloaddition Chemistry; Padwa, A., Ed.; John Wiley and Sons: New York, 1984; Vol. 1.

3. Huisgen, R. J. Org. Chem. 1968, 33, 2291-2297

4. Firestone, R. A. J. Org. Chem. 1968, 33, 2285-2290.

5. Ess. D. H.; Houk, K. N. J. Am. Chem. Soc. 2008, 130, 10198-10187.

6. Schoenebeck, F.; Ess. D. N.; Jones, G. O.; Houk, K. N. J. Am. Chem. Soc. 2009, 131, 8121-8133.

7. Xu, L.; Doubleday, C. E.; Houk, K. N. Angew. Chem. Int. Ed. 2009, 48, 2746-2748.

8. Engels, B.; Christl, M. Angew. Chem. Int. Ed. 2009, 48, 7968-7970.

9. Sustmann, R. Tetrahedron Lett. 1971, 12, 2717-2720.

10. Sustmann, R.; Trill, H. Angew. Chem. Int. Ed. Engl. 1972, 11, 838-840. 
11. Houk, K. N.; Sims, J.; Watts, C. R.; Luskus, L. J. J. Am. Chem. Soc. 1973, 95, 73017315.

12. Houk, K. N. 1,3-Dipolar Cycloaddition Chemistry; Padwa, A., Ed.; John Wiley and Sons: New York, 1984; Vol. 2.

13. Frederickson, M. Tetrahedron, 1997, 53, 403-425.

14. Gothelf, K. V.; Jørgensen, K. A. Chem. Rev. 1998, 98, 863-909.

15. Gothelf, K. V.; Jørgensen, K. A. Chem. Commun. 2000, 1449-1458.

16. Husinec, S.; Savic, V. Tetrahedron: Asymmetry 2005, 16, 2947-2061.

17. Pandey, G.; Banerjee, P.; Gader, S. R. Chem. Rev. 2006, 106, 4484-4517.

18. Pellisier, H. Tetrahedron 2007, 63, 3235-3285.

19. Stanley, L. M.; Sibi, M. P. Chem. Rev. 2008, 108, 2887-2902.

20. Badoiu, A.; Brinkmann, Y.; Viton, F.; Kündig, E. P. Pure Appl. Chem. 2008, 80, 1013-1018.

21. Brandi, A.; Cardona, F.; Cicchi, S.; Cordero, F. M.; Goti, A. Chem. Eur. J. 2009, 15, 7808-7821.

22. Kissane, M.; Maguire, A. R. Chem. Soc. Rev. 2010, 39, 845-883.

23. Carmona, D.; Lamata. M. P.; Viguri. F.; Rodríguez, R.; Oro, L. A.; Lahoz, F. J.; Balana, A. I.; Tejero, T.; Merino, P. J. Am. Chem. Soc. 2005, 127, 13386-13398

24. White, C.; Thompson, S. J.; Maitlis, P. M. J. Chem. Soc., Dalton Trans. 1977, 1654 1661.

25. Tanaka, J.; Kanemasa, S. Tetrahedron 2001, 57, 899-905.

26. Viton, F.; Bernardinelli, G.; Kündig, E. P. J. Am. Chem. Soc. 2002, 124, 4968-4969.

27. Ali, S. A.; Khan, J. H.; Wazeer, M. I. M. Tetrahedron 1988, 44, 5911-5920.

28. Brunner, H. Eur. J. Inorg. Chem. 2001, 905-912.

29. Carmona, D.; Cativiela, C.; Elipe, S.; Lahoz, F. J.; Lamata, M. P.; López-Ram de Víu, M. P.; Oro, L. A.; Vega, C.; Viguri, F. Chem. Commun. 1997, 2351-2352.

30. Kündig, E. P.; Saudan, C. M.; Bernardinelli, G. Angew. Chem., Int. Ed. 1999, 38, $1220-1223$

31. Davenport, A. J.; Davies, D. L.; Fawcett, J.; Garrat, S. A.; Russell, D. R. J. Chem. Soc., Dalton Trans. 2000, 4432-4441.

32. Ishihara, K.; Qingzhi, G.; Yamamoto, H. J. Am. Chem. Soc. 1993, 115, 10412-10413.

33. Mita, T.; Ohtsuki, N.; Ikeno, T.; Yamada, T. Org. Lett. 2002, 4, 2457-2460.

34. Ohtsuki, N.; Kezuka, S.; Kogami, Y.; Mita, T.; Ashizawa, T.; Ikeno, T.; Yamada, T. Synthesis, 2003, 1462-1466.

35. Kezuka, S.; Ohtsuki, N.; Mita, T.; Kogami, Y.; Ashizawa, T.; Ikeno, T.; Yamada, T. Bull. Chem. Soc. Jpn. 2003, 76, 2197-2207.

36. Shirahase, M.; Kanemasa, S.; Oderaotoshi, Y. Org. Lett. 2004, 6, 675-678.

37. Shirahase, M.; Kanemasa, S.; Hasegawa, M. Tetrahedron Lett. 2004, 45, 4061-4063

38. Carmona, D.; Lamata, M. P.; Viguri, F.; Rodríguez, R.; Oro, L. A.; Balana, A. I.; Lahoz, F. J.; Tejero, T.; Merino, P.; Franco, S.; Montesa, I. J. Am. Chem. Soc. 2004, $126,2716-2717$.

39. Kano, T.; Hashimoto, T.; Maruoka, K. J. Am. Chem. Soc. 2005, 127, 11926-11927.

40. Carmona D.; Lamata, M. P.; Viguri, F.; Ferrer, J.; García, N.; Lahoz, F.; Martín, M. L.; Oro, L. A. Eur. J. Inorg. Chem. 2006, 3155-3166. 
41. Carmona D.; Lamata. M. P.; Viguri, F.; Rodríguez, R.; Fischer, T.; Lahoz, F.; Dobrinovitch, I. T.; Oro, L. A. Adv. Synth. Catal. 2007, 349, 1751-1758.

42. Carmona D.; Lamata. M. P.; Viguri, F.; Rodríguez, R.; Lahoz, F.; Oro, L. A. Chem. Eur. J. 2007, 13, 9746-9756.

43. Hashimoto, T.; Omote, M.; Kano, T.; Maruoka, K. Org. Lett. 2007, 9, 4805-4808.

44. Badoiu, A.; Bernardinelli, G.; Mareda, J.; Kündig, E. P.; Viton, F. Chem. Asian J. 2008, 3, 1298-1311.

45. Wang, Y.; Wolf, J.; Zavalij, P.; Doyle, M. P. Angew. Chem. Int. Ed. 2008, 47, 14391442.

46. Carmona D.; Lamata. M. P.; Viguri, F.; Rodríguez, R.; Lahoz, F.; Fabra, M. J.; Oro, L. A. Tetrahedron: Asymmetry. 2009, 20, 1197-1205.

47. With the homologous rhodium complex $\left(S_{\mathrm{Rh}}, R_{\mathrm{C}}\right)-\left[\left(\eta^{5}-\mathrm{C}_{5} \mathrm{Me}_{5}\right) \mathrm{Rh}\{(R)-\right.$ Prophos $\}$ (methacrylonitrile)] $\left(\mathrm{SbF}_{6}\right)_{2}$ as catalyst, up to 10 consecutive catalytic runs have been performed for the reaction between methacrylonitrile and the nitrone 3,4dihydroisoquinoline $N$-oxide (V). Yield decreases from $97 \%$ (first run) to $84 \%$ (tenth run) and enantioselectivity remains essentially constant at $90 \%$ ee. 